\title{
Analisis Kohesi Wacana Naratif “Mendongeng Lima Menit” pada Tabloid Tokoh
}

\author{
Wayan Sri Kusuma Wardani $^{1^{*}}$, I Nyoman Suparwa ${ }^{2}$ \\ ${ }^{[123]}$ Program Studi Sastra Indonesia, Fakultas Ilmu Budaya, Universitas Udayana \\ ${ }^{1}$ [email: wayansrikusumawardani@gmail.com], ${ }^{2}$ [email: suparwa_nym@yahoo.co.id] \\ *Corresponding Author
}

\begin{abstract}
This study entitled "Analisis Kohesi Wacana Naratif 'Mendongeng Lima Menit' pada Tabloid Tokoh". The aims of this study are (1) to identify the lexical cohesive device, (2) to identify the grammatical cohesive device, and (3) to identify the cohesiveness degree of a narrative discourse in "Mendongeng Lima Menit" on Tokoh tabloids. The method used in collecting the data in this study is observation method, and then the data were analyzed with descriptive qualitative method, quantitative method, and distributional method. The method used in presenting the data analysis are formal and informal methods. The source of data in this study is taken from the narrative discourse of "Mendongeng Lima Menit" in Tokoh tabloids, which consists of 27 fairytale stories. This study used the theory of cohesion by Halliday \& R. Hassan in their book Cohesion in English (1976:4). This study found types of lexical cohesion, grammatical cohesion, and the cohesiveness degree in the narrative discourse "Mendongeng Lima Menit" on the tabloids of Tokoh. The lexical cohesion found were synonym, antonym, repetition, colocation, and equivalency. The grammatical cohesion found were reference, substitution, ellipsis, and conjunction. The cohesiveness degree of the narrative discourse "Mendongeng Lima Menit' was high, which was 92,7\% and they were built by 930 cohesive devices. The grammatical cohesion included the 210 references (22,6\%), 44 substitutions (4,7\%), 12 ellipsis (1,3\%), and 528 conjunctions (56,8\%). The lexical cohesion included 6 synonyms $(0,64 \%), 31$ antonyms (3,3\%), 57 repetitions (6,1\%), 36 colocations $(3,9 \%)$, and 6 equivalencies $(0,64 \%)$.
\end{abstract}

Keyword: lexical cohesive, grammatical cohesive, cohesiveness degree

\begin{abstract}
Abstrak
Penelitian ini berjudul "Analisis Kohesi Wacana Naratif "Mendongeng Lima Menit" pada Tabloid Tokoh". Tujuan penelitian ini adalah (1) untuk mengetahui alat-alat kohesi leksikal, (2) untuk mengetahui alat-alat kohesi gramatikal, dan (3) untuk mengetahui tingkat kekohesifan wacana naratif "Mendongeng Lima Menit" pada tabloid Tokoh. Metode yang digunakan untuk mengumpulkan data pada penelitian ini adalah metode simak (observasi), kemudian data dianalisis dengan metode deskriptif kualitatif, metode kuantitatif, dan metode distribusional (agih). Metode penyajian hasil analisis data yang digunakan adalah metode formal dan metode informal. Sumber data penelitian ini adalah wacana naratif "Mendongeng Lima Menit" pada tabloid Tokoh sebanyak 27 dongeng. Landasan teori yang digunakan dalam penelitian ini adalah teori kohesi Halliday \& R. Hassan dalam bukunya Cohesion in English (1976:4). Hasil penelitian ini, yaitu jenis kohesi leksikal, jenis kohesi gramatikal, dan tingkat kekohesifan yang terdapat dalam wacana naratif "Mendongeng Lima Menit" pada tabloid Tokoh. Adapun kohesi leksikal yang ditemukan, yakni sinonim, antonim, repetisi, kolokasi, dan ekuivalensi. Kohesi gramatikal yang ditemukan, yakni referensi, substitusi, elipsis, dan konjungsi. Tingkat kekohesifan wacana naratif "Mendongeng Lima Menit" pada tabloid Tokoh tergolong tinggi, yaitu 92,7\% yang dibangun oleh 930 alat kohesi. Kohesi gramatikal meliputi sarana referensi
\end{abstract}


sebanyak 210 buah (22,6\%), sarana substitusi sebanyak 44 buah $(4,7 \%)$, sarana elipsis sebanyak 12 buah $(1,3 \%)$, dan sarana konjungsi sebanyak 528 buah $(56,8 \%)$. Kohesi leksikal meliputi sarana sinonim sebanyak 6 buah $(0,64 \%)$, sarana antonim sebanyak 31 buah $(3,3 \%)$, sarana repetisi sebanyak 57 buah $(6,1 \%)$, sarana kolokasi sebanyak 36 buah $(3,9 \%)$, dan sarana ekuivalensi sebanyak 6 buah $(0,64 \%)$.

Kata kunci: kohesi leksikal, kohesi gramatikal, tingkat kekohesifan

\section{Latar Belakang}

Wacana naratif adalah bentuk wacana yang banyak digunakan untuk menceritakan suatu kisah. Uraiannya cenderung ringkas. Bagian-bagian yang dianggap penting sering diberikan tekanan atau diulang. Bentuk wacana naratif umumnya dimulai dengan alinea pembuka, isi, dan diakhiri dengan alinea penutup.

Dongeng merupakan salah satu bentuk wacana naratif yang bersifat fiksi (rekaan). Berdasarkan media penyampaiannya, dongeng tidak hanya disampaikan secara lisan, tetapi juga dapat disampaikan secara tertulis, contohnya "Mendongeng Lima Menit" pada tabloid mingguan Tokoh.Tabloid Tokoh merupakan anak perusahaan Bali Post di samping tabloid Lintang, tabloid Wiyata Mandala, dan majalah Bali Post.

Hal yang menarik dari dongeng adalah penggunaan unsur bahasa dalam menceritakan suatu kisah. Bahasa yang digunakan memiliki karakteristik yang menarik, meliputi kata, frasa, dan kalimat sehingga menghasilkan kepaduan wacana. Unsur kepaduan (kohesi) tersebut dapat menceritakan alur cerita sehingga dimengerti dan dipahami oleh pembaca.

Alasan pemilihan objek kajian mengenai wacana naratif "Mendongeng Lima Menit" pada tabloid Tokoh, yakni (1) mendongeng pada era modern sudah jarang dilakukan oleh para orang tua karena tuntutan kesibukan dalam pekerjaan, (2) wacana naratif "Mendongeng Lima Menit" sangat mudah didapatkan karena dongeng tersebut terbit setiap minggu pada tabloid Tokoh, (3) tabloid Tokoh merupakan tabloid yang diminati oleh sebagian besar masyarakat Bali karena tabloid Tokoh merupakan terbitan Bali Post yang memiliki oplah terbesar dalam pendistribusian surat kabar di Bali, (4) bahasa yang digunakan oleh pengarang memiliki karakteristik yang menarik jika ditinjau dari segi bentuk (alat-alat kohesinya), (5) selain memiliki karakteristik bahasa yang menarik, "Mendongeng Lima Menit" pada tabloid Tokoh bersifat kekinian karena topik yang diceritakan sesuai dengan situasi dan kondisi kehidupan saat ini, (6) "Mendongeng Lima Menit" merupakan dongeng masa kini yang alur ceritanya sangat singkat sehingga tidak memerlukan waktu lama untuk membaca dan memahami isinya.

\section{Pokok Permasalahan}

Berdasarkan latar belakang di atas terdapat tiga pokok permasalahan yang dibahas dalam penelitian ini. Ketiga masalah tersebut adalah sebagai berikut.

a) Apa sajakah alat-alat kohesi leksikal wacana naratif "Mendongeng Lima Menit" pada tabloid Tokoh?

b) Apa sajakah alat-alat kohesi gramatikal wacana naratif "Mendongeng Lima Menit" pada tabloid Tokoh?

c) Bagaimanakah tingkat kekohesifan wacana naratif "Mendongeng Lima Menit" pada tabloid Tokoh? 


\section{Tujuan Penelitian}

Secara umum, penelitian ini bertujuan untuk menambah wawasan dalam bidang kebahasaan, khususnya analisis wacana. Secara khusus penelitian ini memiliki tiga tujuan, yaitu untuk mengetahui alat-alat kohesi leksikal wacana naratif "Mendongeng Lima Menit" pada tabloid Tokoh, untuk mengetahui alat-alat kohesi gramatikal wacana naratif "Mendongeng Lima Menit" pada tabloid Tokoh, dan untuk mengetahui tingkat kekohesifan wacana naratif "Mendongeng Lima Menit" pada tabloid Tokoh.

\section{Metode Penelitian}

Pengumpulan data pada penelitian inimenggunakan metode simak dan dilanjutkan dengan teknik catat. Pada tahap analisis data digunakan metode agih dan dilanjutkan dengan teknik lesap dan teknik ganti. Hasil analisis data disajikan dengan dua cara, yakni metode formal dan metode informal.

\section{Hasil dan Pembahasan}

Pembahasan pada penelitian inidilakukan dengan membagi data berdasarkan unsur-unsur yang dikandungnya, yakni alat-alat kohesi leksikal, alat-alat kohesi gramatikal, dan tingkat kekohesifan wacana. Data yang diteliti adalah wacana naratif "Mendongeng Lima Menit" pada tabloid Tokoh edisi Mei-Oktober 2017.

\subsection{Kohesi Leksikal}

Kohesi leksikal adalah salah satu hal yang mendukung keutuhan wacana. Menurut Sumarlam (2003:35) kohesi leksikal adalah hubungan antarunsur dalam wacana secara semantis. Kohesi leksikal terdiri atas padan kata (sinonim), lawan kata (antonim), pengulangan (repetisi), sanding kata (kolokasi), dan kesepadanan (ekuivalensi).

\subsubsection{Sinonim}

Sinonim adalah kata-kata yang mempunyai kemiripan makna dengan bentuk yang berbeda (Tarigan, 2009:161). Fungsi sinonim adalah untuk menjalin hubungan makna yang sepadan antara satuan lingual tertentu dan satuan lingual yang lain dalam wacana (Sumarlam, 2003:39). Berikut ini adalah penggunaan aspek sinonim wacana naratif "Mendongeng Lima Menit" pada tabloid Tokoh.

(1) "Sahabatku Air!" kata Matahari pada suatu hari. "Aku sering berkunjung ke rumahmu, tetapi kamu tak pernah bertandang ke rumahku" ( Tokoh, 3-9 Juli 2017, Matahari dan Air).

Pada data (1) terdapat kata kerja berkunjung dan bertandang. Kedua kata tersebut secara makna mengungkapkan hubungan sinonim karena mengacu pada arti yang sama. Makna kata berkunjung adalah 'pergi untuk menengok atau menjumpai seseorang di suatu tempat' dan makna kata bertandang adalah 'bertamu ke rumah orang'. Kata berkunjung dan bertandang sama-sama bermakna menjumpai seseorang di suatu tempat.

\subsubsection{Antonim}

Satuan lingual yang maknanya berlawanan atau beroposisi dengan lingual yang lain (Sumarlam, 2003:40). Berikut ini dijelaskan data mengenai aspek antonim dalam wacana naratif "Mendongeng Lima Menit" pada tabloid Tokoh.

(2) Dalam rapat yang dipimpin Klian Desa, para warga tak henti-hentinya memuji tindakan gagak yang pemberani itu. Beberapa warga mengusulkan agar mulai saat itu para warga tidak memandang gagak sebagai musuh dan sebagai pertanda maut, tetapi sebagai sahabat. Gagak yang berbulu hitam dan kotor adalah simbol penolong dan pekerja keras. 
Kekelik yang berbulu abu-abu dan bersih adalah pertanda kemalasan dan suka mencuri. Perjuangan gagak menolong warga, juga mendorong para petani untuk membuat serokan mulai dari telaga sampai ke sawah. Dengan demikian sawah tetap berair dan dapat ditanami padi (Tokoh, 29 Mei--4 Juni 2017, Gagak dan Kekelik).

Pada data (2) terdapat nomina musuh dan sahabat. Kedua kata tersebut secara makna mengungkapkan hubungan antonim karena mengacu pada makna yang berlawanan. Nomina musuh dan sahabat termasuk oposisi hubungan karena bersifat saling melengkapi. Makna kata musuh adalah 'lawan', sedangkan makna kata sahabat adalah 'teman dekat'. Adanya oposisi hubungan dalam data tersebut dapat mendukung kepaduan wacana secara leksikal untuk menghasilkan wacana yang kohesif.

\subsubsection{Repetisi}

Repetisi adalah pengulangan satuan lingual (bunyi, suku kata, kata, atau bagian kalimat) yang dianggap penting untuk memberikan tekanan dalam sebuah konteks yang sesuai (Sumarlam, 2003:35). Berikut ini dijelaskan data pengulangan (repetisi) dalam wacana naratif "Mendongeng Lima Menit" pada tabloid Tokoh.

(3) "Waduh!" seru Bambu Buluh itu tiba-tiba setelah menoleh ke sebelah. Di situ tampak tergeletak sebuah pohon besar yang mengaku paling tinggi dan paling berguna (Tokoh, 9-15 Oktober 2017, Pohon Kapuk dan Bambu Buluh).

Pada data (3) terdapat pengulangan adverbia, yakni kata paling. Kata paling bermakna 'teramat atau sangat'. Pengulangan kata paling pada data di atas dilakukan untuk menekankan bahwa kata tersebut penting dalam wacana. Pengulangan tersebut merupakan sarana yang dilakukan agar wacana menjadi kohesif.

\subsubsection{Kolokasi}

Kolokasi adalah asosiasi tertentu dalam pilihan kata yang cenderung digunakan secara berdampingan, yaitu kata-kata yang dipakai dalam satuan domain atau jaringan tertentu (Sumarlam, 2003:44). Berikut ini disajikan penggunaan aspek kolokasi dalam wacana naratif "Mendongeng Lima Menit" pada tabloid Tokoh.

(4) Si Sulung menjual sebagian tanah warisannya. Di sebuah dataran ia membangun sebuah rumah yang kokoh. Semua kerangka dibuat dari besi beton, tembok dari batako dan atap dari besi baja ringan (Tokoh,4-10 September 2017, Gempa Bumi Dahsyat).

Pada data (4) tampak adanya katakata yang berkolokasi, yakni kata besi beton, tembok, batako, atap, dan besi baja. Kata-kata tersebut berkolokasi karena berada dalam suatu domain atau jaringan tertentu, yaitu bahan bangunan.

\subsubsection{Ekuivalensi}

Ekuivalensi adalah kesepadanan antara satuan lingual tertentu dan satuan lingual yang lain dalam sebuah paradigma (Sumarlam, 2003:46). Berikut ini disajikan penggunaan aspek ekuivalensi dalam wacana naratif "Mendongeng Lima Menit" pada tabloid Tokoh.

(5) Kedua kambing itu sudah lama berkenalan dan saling kenalmengenal. Tetapi mereka berdua tidak pernah melihat wajah kenalannya itu. Hal itu disebabkan karena kedua rumah bertetangga itu dibatasi tembok setinggi manusia. Di atas tembok dipasangi kawat berduri berhiaskan tumbuhan rambat. Jadi mereka berdua hanya berbincangbincang dengan embikan masing- 
masing (Tokoh, 28 Agustus--3 September 2017, Dua Kambing Kasmaran).

Pada data (5) terdapat kata berkenalan, kenal-mengenal, dan kenalannya memiliki kesepadanan antarsatuan lingual. Hubungan kesepadanan ditunjukkan oleh kata hasil proses afiksasi morfem-morfem yang sama. Makna kata berkenalan sebagai verba, yakni 'bersalaman agar saling mengenal', makna kata kenal-mengenal sebagai verba yang merupakan kata ulang (reduplikasi) memiliki makna 'saling mengetahui satu dengan lainnya', dan kata kenalannya sebagai nomina yang memiliki makna 'orang yang sudah dikenal'. Jadi, kata dasar berkenalan, kenal-mengenal, dan kenalannya pada data (17) adalah kenal yang berarti 'tahu'.

\subsection{Kohesi Gramatikal}

Kohesi gramatikal adalah hubungan kohesif dalam wacana yang dicapai dengan penggunaan elemen dan sistem gramatikal atau hubungan antarunsur. Kohesi gramatikal meliputi referensi, substitusi, elipsis, dan konjungsi.

\subsubsection{Referensi}

Referensi (pengacuan) dibagi menjadi tiga macam, yakni pengacuan persona, pengacuan demonstratif, dan pengacuan komparatif. Berikut ini contoh penggunaan aspek referensi dalam wacana naratif "Mendongeng Lima Menit" pada tabloid Tokoh.

(6) "Jangan mengolok-olok, Sahabat!" jawab Abdullah. "Aku kehilangan barang yang sangat mahal, oleh karena itu aku sangat sedih" (Tokoh, 25 September-1 Oktober 2017, Sebongkah Emas).

Pada data (6) terdapat referensi pronomina persona, yaitu Aku. Pronomina persona I tunggal bentuk bebas aku mengacu pada seorang tokoh di dalam teks, yaitu Abdullah. Unsur aku pada data (6) termasuk endofora yang bersifat anafora karena mengacu ke dalam teks itu sendiri serta merujuk pada unsur yang telah disebutkan sebelumnya.

(7) "Waduh!" seru Bambu Buluh itu tiba-tiba setelah menoleh ke sebelah.

Di situ tampak tergeletak sebuah pohon besar yang mengaku paling tinggi dan paling berguna (Tokoh, 9-15 Oktober 2017, Pohon Kapuk dan Bambu Buluh).

Pada data (7) baris kedua terdapat unsur di situ yang merujuk pada suatu tempat di luar teks. Unsur di situ termasuk eksofora karena merujuk ke suatu tempat di luar teks.

(8) Di sebuah kota besar tinggal dua keluarga bertetangga. Nama masingmasing kepala keluarga itu adalah Tuan Anton dan Tuan Barus. Kebetulan saja, keluarga itu mempunyai kegemaran yang sama, yakni memelihara kambing. (Tokoh, 28 Agustus--3 September 2017, Dua Kambing Kasmaran).

Selanjutnya, terdapat unsur sama pada data (8) yang merupakan perbandingan dari dua hobi, yaitu memelihara kambing. Unsur sama pada data (8) termasuk endofora yang bersifat katafora karena merujuk pada penjelasan selanjutnya, yakni memelihara kambing.

\subsubsection{Substitusi}

Substitusi adalah proses atau hasil penggantian unsur bahasa dengan unsur lain dalam satuan yang lebih besar untuk memperoleh unsur-unsur pembeda atau unsur yang menjelaskan suatu unsur tertentu (Kridalaksana, 2008:229).Berikut ini dijelaskan substitusi dalam wacana naratif "Mendongeng Lima Menit" pada tabloid Tokoh.

(9) Namun pada suatu hari, terdengar berita yang menyedihkan. Raja 
Bedahulu tiba-tiba dirundung duka karena kuda kesayangannya hilang dari kandangnya. Beliau memerintahkan kepada menterinya agar mencari kuda itu. Berhari-hari, berbulan-bulan, tak ada tanda-tanda kuda itu ditemukan (Tokoh, 23--29 Oktober 2017, Kuda Oncesrawa).

Selanjutnya, pada data (9) terdapat penggantian dari frasa nominalRaja Bedahulu ke nomina beliau. Hal ini terjadi untuk menciptakan kalimat yang bervariasi dan menghindari pengulangan kata.

\subsubsection{Elipsis}

Elipsis (penghilangan atau pelesapan) adalah proses penghilangan kata atau satuan-satuan kebahasaan lain. Bentuk atau unsur yang dilesapkan dapat diperkirakan wujudnya dari konteks bahasa atau konteks luar bahasa (Kridalaksana dalam Mulyana, 2009:28). Berikut uraian dan penjelasan mengenai unsur yang dihilangkan pada wacana naratif "Mendongeng Lima Menit" pada tabloid Tokoh.

(10a) Di sekelilingnya tumbuh banyak bunga, namun bunga-bunga itu semua berwarna hijau, sama dengan warna daunnya. Tambah lagi $\emptyset$ tidak berbau sama sekali (Tokoh, 11--17 September 2017, Warna dan Bau Bunga).

(10b) Di sekelilingnya tumbuh banyak bunga, namun bunga-bunga itu semua berwarna hijau, sama dengan warna daunnya. Tambah lagi bunga-bunga itu tidak berbau sama sekali.

Pada (10a) terdapat penghilangan satuan lingual berupa frasa, yakni bungabunga itu. Penghilangan pada frasa tersebut dilakukan agar penjelasan lebih efisien. Selain itu, frasa tersebut dihilangkan untuk mencapai nilai ekonomis dalam pemakaian bahasa serta membentuk wacana yang efektif.

\subsubsection{Konjungsi}

Konjungsi (kata sambung) adalah bentuk atau satuan kebahasaan yang berfungsi sebagai penyambung, perangkai, atau penghubung antara kata dan kata, frasa dan frasa, klausa dan klausa, kalimat dan kalimat (Kridalaksana dalam Mulyana, 2009:29).Berikut konjungsi yang terdapat pada wacana naraif "Mendongeng Lima Menit" pada Tabloid Tokoh.

(11) Tersebutlah satu keluarga kodok yang berbahagia. Sejak kakekneneknya terdahulu, mereka mendiami sudut sawah dekat serokan dan semak-semak. Mereka merasa memiliki sawah itu, dan menganggap keluarga kodok adalah keluarga terhormat (Tokoh, 8--14 Mei 2017, Ibu Kodok dan Kerbau).

Pada data (11) terdapat konjungsi dan yang termasuk konjungsi koordinatif. Kata dan berfungsi menyatakan hubungan penambahan antara frasa 'dekat serokan' dengan kata ulang 'semak-semak' yang setara kedudukannya.

\subsection{Tingkat Kekohesifan Wacana Naratif "Mendongeng Lima Menit" pada tabloid Tokoh}

Untuk mewujudkan sebuah wacana yang kohesif dibutuhkan sarana-sarana kohesi yang digunakan secara tepat. Menurut Chaer (2007:267), "kekohesifan, yaitu adanya keserasian hubungan unsur-unsur yang ada dalam wacana tersebut". Dengan kata lain, wacana dapat dipahami maksudnya karena adanya bentuk bahasa, yaitu apa yang dituliskan dan ditafsirkan pembaca. Jumlah kalimat dalam wacana naratif "Mendongeng Lima Menit" pada Tabloid Tokoh sebanyak 1.003 buah. Secara keseluruhan kalimat-kalimat tersebut dirangkai dan dibangun oleh 930 buah 
alat kohesi. Berdasarkan hal tersebut, tingkat kekohesifan wacana naratif "Mendongeng Lima Menit" pada tabloid Tokoh tergolong tinggi, yakni sebesar 92,7\%. Hal tersebut mencerminkan bahwa wacana naratif "Mendongeng Lima Menit" pada tabloid Tokoh tergolong kohesif. Adapun alat kohesi yang berperan dalam membangun kekohesifan wacana naratif "Mendongeng Lima Menit" pada tabloid Tokoh terdiri atas alat kohesi gramatikal sebanyak 794 buah $(85,4 \%)$ dan kohesi leksikal sebanyak 136 buah (14,58\%).

Perolehan persentase peranti kohesi gramatikal, yaitu 210 buah $(22,6 \%)$ referensi, 44 buah $(4,7 \%)$ substitusi, 12 buah $(1,3 \%)$ elipsis, dan 528 buah $(56,8 \%)$ konjungsi. Adapun perolehan persentase kohesi leksikal, yaitu 6 buah $(0,64 \%)$ sinonim, 31 buah $(3,3 \%)$ antonim, 57 buah $(6,1 \%)$ repetisi, 36 buah $(3,9 \%)$ kolokasi, dan 6 buah $(0,64 \%) \quad$ ekuivalensi. Konjungsi merupakan kohesi yang paling banyak digunakan dalam membangun kekohesifan wacana naratif "Mendongeng Lima Menit" pada tabloid Tokoh. Adapun alat kohesi yang paling sedikit digunakan, yakni sinonim dan ekuivalensi.

\section{Simpulan}

Alat-alat kohesi wacana naratif "Mendongeng Lima Menit" pada tabloid Tokoh meliputi alat kohesi leksikal dan alat kohesi gramatikal. Alat kohesi leksikal yang ditemukan, yakni sinonim, antonim, repetisi, kolokasi, dan ekuivalensi. Alat kohesi gramatikal yang ditemukan, yakni referensi, substitusi, elipsis, dan konjungsi. Kemudian, tingkat kekohesifan wacana naratif "Mendongeng Lima Menit" pada tabloid Tokoh tergolong tinggi, yakni 92,7\%. Hal tersebut mencerminkan bahwa wacana naratif "Mendongeng Lima Menit" pada tabloid Tokoh tergolong kohesif.

\section{Daftar Pustaka}

Alwi, Hasan dkk. 2010. Tata Bahasa Baku Bahasa Indonesia. Jakarta: Balai Pustaka.

Chaer, Abdul. 2003. Linguistik Umum. Jakarta: Rineka Cipta.

Djajasudarma, T. Fatimah. 2006. Metoda Linguistik: Ancangan Metoda Penelitian dan Kajian. Bandung: PT Rafika Aditama.

Kridalaksana, Harimurti. 2008. Kamus Linguistik. Jakarta: Gramedia Pustaka Utama.

Mulyana. 2005. Kajian Wacana. Yogyakarta: Tiara Wacana.

Rani, Abdul dkk. 2010. Analisis Wacana (Sebuah Kajian Bahasa dalam Pemakaian). Yogyakarta: Tiara Wacana.

Sudaryanto. 1993. Metode dan Aneka Teknik Analisis Bahasa. Yogyakarta: Duta Wacana University Press.

Sumarlam. 2003. Teori dan Praktik Analisis Wacana. Surakarta: Pustaka Cakra Surakarta.

Tarigan, Henry Guntur. 2009.

Pengajaran Wacana. Bandung: Angkasa.

Verhaar, J.W.M. 2012. Asas-Asas Linguistik Umum. Yogyakarta: Gadjah Mada University Press. 